\title{
Completion pneumonectomy is safe and effective in select patients with recurrent non-small cell lung cancer
}

\author{
Abby White ${ }^{1}$, Suden Kucukak ${ }^{1}$, Daniel N. Lee ${ }^{1}$, Raphael Bueno ${ }^{1}$, Michael Jaklitsch ${ }^{1}$, Steven Mentzer ${ }^{1}$, \\ David Sugarbaker ${ }^{2}$, Jon Wee ${ }^{1}$, Scott J. Swanson ${ }^{1}$ \\ ${ }^{1}$ Division of Thoracic Surgery, Brigham and Women's Hospital, Boston, Massachusetts, USA; ${ }^{2}$ Division of General Thoracic Surgery, Baylor College \\ of Medicine, Houston, Texas, USA \\ Contributions: (I) Conception and design: A White, SJ Swanson; (II) Administrative support: S Kucukak, DN Lee; (III) Provision of study materials \\ or patients: R Bueno, M Jaklitsch, S Mentzer, D Sugarbaker, J Wee, SJ Swanson; (IV) Collection and assembly of data: A White, S Kucukak, DN \\ Lee; (V) Data analysis and interpretation: A White, S Kucukak, DN Lee, SJ Swanson; (VI) Manuscript writing: All authors; (VII) Final approval of \\ manuscript: All authors. \\ Correspondence to: Dr. Abby White, DO. Division of Thoracic Surgery, Brigham and Women's Hospital, 75 Francis Street, Boston, Massachusetts \\ 02090, USA. Email: awhite12@bwh.harvard.edu.
}

Background: Locoregional recurrence rates for non-small cell lung cancer (NSCLC) remain high, even following curative surgical resection. While national guidelines advocate surgical resection for locoregional recurrence, it is rarely offered when resection would require completion pneumonectomy, which available literature associates with a $12-36 \%$ perioperative mortality and $40-80 \%$ morbidity. Additionally, survival advantages to radical surgery in this scenario are largely unknown, particularly because available series often include patients undergoing completion pneumonectomy for benign indications or metastatic disease from other primary sites, making extrapolation to primary lung cancer patients challenging. As systemic therapy options continue to evolve, particularly as it relates to immunotherapy, we expect that there will be more and more opportunities for locoregional surgical control. The aim of this study was to evaluate outcomes following completion pneumonectomy for recurrent NSCLC.

Methods: We retrospectively reviewed all patients who underwent completion pneumonectomy for recurrent NSCLC at our institution between 2000 and 2015. Factors affecting perioperative morbidity and mortality, as well as overall survival, were analyzed.

Results: Between 2000 and 2015, 28 patients underwent completion pneumonectomy for recurrent lung cancer (14 female, 14 male). The median age was 64.2 years (range, 36.7-84.0). There were 11 left-sided and 17 right-sided operations. Fourteen patients (50.0\%) underwent chemotherapy or chemoradiotherapy prior to surgery. Perioperative morbidity was seen in 13 of 28 (46.4\%) patients, and atrial fibrillation was the most common complication. Mortality at 30- and 90-day intervals was 3.6\%, and $14.3 \%$ respectively. Five-year overall survival was $43.1 \%$ and was not associated with preoperative chemotherapy or chemoradiotherapy use. Patients over 70 years old $(n=5)$ experienced a statistically higher rate of postoperative complications (100.0\% vs. $34.8 \%, \mathrm{P}=0.013)$, and this translated into a higher mortality rate at 60 and 90 days. Left-sided resections were associated with increased risk of recurrent laryngeal nerve injury (RLN) compared to rightsided resections ( $36.4 \%$ vs. $0 \%, \mathrm{P}=0.016$ ), and those patients with $\mathrm{RLN}$ injury were more likely to be reintubated (50.0\% vs. 4.2\%, $\mathrm{P}=0.04)$. Bronchopleural fistula occurred in 1 patient $(3.6 \%)$.

Conclusions: Completion pneumonectomy is a viable treatment option for patients with recurrent NSCLC. We attribute our low risks of major morbidity, such as bronchopleural fistula, to careful patient selection and technique. In patients over 70 years, morbidity is higher which should inform discussion regarding surgical options. 
Keywords: Lung cancer; surgical technique; perioperative complications

Submitted Jun 27, 2019. Accepted for publication Dec 10, 2019.

doi: $10.21037 /$ jtd.2020.01.51

View this article at: http://dx.doi.org/10.21037/jtd.2020.01.51

\section{Introduction}

Locoregional recurrence following surgical resection for non-small cell lung cancer (NSCLC) varies according to stage, but affects upwards of $30 \%$ of patients following curative (R0) surgery (1-5). National Cancer Care Network (NCCN) guidelines (6) advocate surgery for locoregional recurrence in patients without evidence of distant disease, but completion pneumonectomy, specifically for recurrent cancer, is sparingly represented in available literature (713). Published studies demonstrate mortality rates up to $36 \%$ and substantial morbidity, but often include patients undergoing completion pneumonectomy for benign lesions, primary lung cancer and metastatic disease indications, making extrapolation to the NSCLC population challenging. We sought to evaluate perioperative outcomes and survival among patients who underwent completion pneumonectomy for recurrent NSCLC, with and without preoperative chemotherapy or chemoradiotherapy.

\section{Methods}

This study was approved by institutional review board of Brigham and Women's Hospital (No. 2006P002482). We reviewed records from all patients who underwent completion pneumonectomy for recurrent NSCLC at our institution between 2000-2015. Patient demographics, morbidity and mortality statistics and survival data were extracted from the medical record into a database. Preoperative chemotherapy or chemoradiotherapy data were also collated. Statistical analysis was performed using STATA 14.1 (Stata Statistical Software, College Station, TX: StataCorp LP). Comparative analysis was performed with the Chi-Square test. Survival was calculated using the Kaplan-Meier method and was statistically evaluated by the log-rank test. A P value of less than 0.05 was considered significant.

\section{Results}

A total of 31 patients underwent completion pneumonectomy for suspected recurrent NSCLC between 2000 and 2015. On final pathologic review, three patients were believed to have new, unrelated second primary lung cancers and were eliminated from the overall survival analysis, leaving 28 patients for analysis. This included 14 women and 14 men (Table 1). Median time from index surgery was 34 months (range, 5-228 months). Median age at surgery was 64.2 years. There were 11 leftsided and 17 right-sided resections. The most common prior resection was a right upper lobectomy ( $\mathrm{n}=8,28.6 \%)$, followed by left lower lobectomy ( $\mathrm{n}=6,21.4 \%)$. Two patients had undergone prior bilobectomy. Four patients (14.3\%) had positive resection margins noted on final path following their index procedure (prior to completion pneumonectomy). One patient had documented N2 disease at the time of initial resection.

Patients considered for completion pneumonectomy for this indication undergo a thorough evaluation prior to surgery. All patients had a recent computed tomography (CT) scan prior to surgery. Twenty patients (71.4\%) underwent pre-pneumonectomy positron emission tomography (PET) scanning and two underwent prepneumonectomy bone scans, as was the standard practice at this institution prior to 2003. All patients underwent preoperative pulmonary function studies. Median percent predicted FEV1 was $72 \%$. Nineteen patients (67.9\%) underwent preoperative echocardiogram. All patients examined by echocardiogram had documented normal right and left ventricular function. The lowest documented ejection fraction was 53\% (range, 53-72\%).

All patients underwent standard posterolateral thoracotomy. Most patients underwent intrapericardial dissection for control of hilar structures during pneumonectomy $(\mathrm{n}=18,64.3 \%)$. Nearly all mainstem staple lines were reinforced with a soft tissue buttress $(\mathrm{n}=25,89.3 \%)$, most commonly with pericardium ( $\mathrm{n}=13,46.4 \%)$, followed by thymic fat pad $(\mathrm{n}=6,21.4 \%)$, and intercostal muscle $(\mathrm{n}=5,17.9 \%)$ (Table 2). Median length of stay was 8 days. Fourteen patients received chemotherapy, radiotherapy or both prior to pneumonectomy. The majority of patients were N0 following pneumonectomy. Six patients (21.4\%) exhibited $\mathrm{N} 1$ nodal disease on final pathology, and one patients had $\mathrm{N} 2$ disease (3.6\%). Two patients (7.1\%) had final positive margins after completion pneumonectomy, one at the chest 
Table 1 Clinical and pathological characteristics of patients undergoing completion pneumonectomy for recurrent NSCLC

\begin{tabular}{|c|c|}
\hline Patient characteristic & Value $(n=28)$ \\
\hline \multicolumn{2}{|l|}{ Age (years) } \\
\hline Mean $( \pm \mathrm{SD})$ & $62.9( \pm 11.23)$ \\
\hline Median & 64.2 \\
\hline Min & 36.7 \\
\hline Max & 84.0 \\
\hline \multicolumn{2}{|l|}{ Gender, n (\%) } \\
\hline Female & $14(50.0)$ \\
\hline Male & $14(50.0)$ \\
\hline \multicolumn{2}{|l|}{ Smoker, n (\%) } \\
\hline Never & 5 (17.9) \\
\hline Current & $6(21.4)$ \\
\hline Former & $14(50.0)$ \\
\hline No info & $3(10.7)$ \\
\hline \multicolumn{2}{|l|}{ FEV\% } \\
\hline Mean $( \pm \mathrm{SD})$ & $72.72( \pm 17.61)$ \\
\hline Median & 72 \\
\hline Min & 38 \\
\hline Max & 102 \\
\hline \multicolumn{2}{|l|}{ Tumor size $(\mathrm{cm})$} \\
\hline Mean $( \pm S D)$ & $3.2( \pm 2.50)$ \\
\hline Median & 2.8 \\
\hline Max & 10.5 \\
\hline \multicolumn{2}{|l|}{ Prior resection, n (\%) } \\
\hline RUL & $8(28.6)$ \\
\hline LLL & $6(21.4)$ \\
\hline RLL & 5 (17.9) \\
\hline Sublobar resection & $6(21.4)$ \\
\hline LUL & $1(3.6)$ \\
\hline Bilobectomy & $2(7.1)$ \\
\hline \multicolumn{2}{|c|}{ Time from prior resection (months) } \\
\hline Mean $( \pm \mathrm{SD})$ & $56.6( \pm 63.35)$ \\
\hline Median & 34.0 \\
\hline
\end{tabular}

NSCLC, non-small cell lung cancer; SD, standard deviation; RUL, right upper lobe; LLL, left lower lobe; RLL, right lower lobe; LUL, left upper lobe.
Table 2 Dissection and buttress characteristics during completion pneumonectomy for recurrent NSCLC ( $\mathrm{N}=28)$

\begin{tabular}{lcc}
\hline Buttress technique & No. of patients & $\%$ \\
\hline Intrapericardial dissection & 18 & 64.3 \\
Buttress to bronchial stump & 3 & \\
None & 13 & 46.4 \\
Pericardium & 6 & 21.4 \\
Thymic fat pad & 5 & 17.9 \\
Intercostal muscle & 1 & 3.6 \\
Pleura & &
\end{tabular}

Table 3 Survival following completion pneumonectomy for recurrent NSCLC $(\mathrm{n}=28)$

\begin{tabular}{|c|c|c|c|}
\hline Characteristic & $\begin{array}{c}\text { Number of } \\
\text { patients, n (\%) }\end{array}$ & $\begin{array}{c}\text { Survival at } \\
5 \text { years, n (\%) }\end{array}$ & $\begin{array}{c}\text { 90-day } \\
\text { mortality, n (\%) }\end{array}$ \\
\hline \multicolumn{4}{|l|}{ Laterality } \\
\hline Left & $11(39.3)$ & $3(36.4)$ & $2(18.2)$ \\
\hline Right & $17(60.7)$ & $5(44.3)$ & $2(11.8)$ \\
\hline$P$ value & & 0.565 & 1.000 \\
\hline \multicolumn{4}{|l|}{ Age } \\
\hline$<70$ years & $23(82.1)$ & $7(45.5)$ & $1(4.4)$ \\
\hline$>70$ years & $5(17.9)$ & $1(20.0)$ & $3(60.0)$ \\
\hline$P$ value & & 0.019 & 0.011 \\
\hline \multicolumn{4}{|c|}{ Pre-pneumonectomy therapy } \\
\hline $\begin{array}{l}\text { No other } \\
\text { treatment }\end{array}$ & $14(50.0)$ & $5(43.7)$ & $3(21.4)$ \\
\hline Chemo only & $7(25.0)$ & $2(35.7)$ & $1(14.3)$ \\
\hline Radiation only & $1(3.6)$ & $0(0.0)$ & $0(0.0)$ \\
\hline CRT & $6(21.4)$ & $1(55.6)$ & $0(0.0)$ \\
\hline$P$ value & & 0.543 & 0.596 \\
\hline
\end{tabular}

NSCLC, non-small cell lung cancer; CRT, chemoradiotherapy.

wall margin and one at the bronchial margin.

Overall survival at 5 years was $43.1 \%$ (Table 3). Mortality at 30 days was $3.6 \%$ and at 90 days was $14.3 \%(n=4)$ and did not differ according to laterality of resection.

Pre-pneumonectomy chemoradiation was not associated with a difference in survival or morbidity. Postoperative complication rate was $46.4 \%$ (Table 4). Patients over 
Table 4 Perioperative complications following completion pneumonectomy for recurrent NSCLC

\begin{tabular}{|c|c|c|c|c|c|c|c|}
\hline Perioperative complications & \multicolumn{2}{|c|}{ Right lung (N=17) } & \multicolumn{2}{|c|}{ Left lung $(\mathrm{N}=11)$} & \multicolumn{2}{|c|}{ Total $(\mathrm{N}=28)$} & $P$ value \\
\hline Overall complications & 8 & 47.1 & 5 & 45.5 & 13 & 46.4 & 1.000 \\
\hline Afib/SVT & 6 & 35.3 & 2 & 18.2 & 8 & 28.6 & 0.419 \\
\hline Empyema & 0 & 0.0 & 0 & 0.0 & 0 & 0.0 & $\mathrm{n} / \mathrm{a}$ \\
\hline BPF & 1 & 5.9 & 0 & 0.0 & 1 & 3.6 & 1.000 \\
\hline PE & 0 & 0.0 & 2 & 18.2 & 2 & 7.1 & 0.146 \\
\hline Pneumonia & 0 & 0.0 & 1 & 9.1 & 1 & 3.6 & 0.393 \\
\hline DVT & 0 & 0.0 & 2 & 18.2 & 2 & 7.1 & 0.146 \\
\hline C. diff & 0 & 0.0 & 0 & 0.0 & 0 & 0.0 & $\mathrm{n} / \mathrm{a}$ \\
\hline ARF & 0 & 0.0 & 0 & 0.0 & 0 & 0.0 & $\mathrm{n} / \mathrm{a}$ \\
\hline Ventilation $>7$ days & 1 & 5.9 & 0 & 0.0 & 1 & 3.6 & 1.000 \\
\hline Reintubation & 1 & 5.9 & 2 & 18.2 & 3 & 10.7 & 0.543 \\
\hline RLN paresis & 0 & 0.0 & 4 & 36.4 & 4 & 14.3 & 0.016 \\
\hline Take back to OR & 2 & 11.8 & 1 & 9.1 & 3 & 10.7 & 1.000 \\
\hline Readmit & 3 & 17.7 & 2 & 18.2 & 5 & 17.9 & 1.000 \\
\hline
\end{tabular}

NSCLC, non-small cell lung cancer; Afib, atrial fibrillation; SVT, supraventricular tachycardia; ARDS, acute respiratory distress syndrome; BPF, bronchopleural fistula; PE, pulmonary embolism; DVT, deep venous thrombosis; MI, myocardial infarction; C. diff, Clostridium difficile; ARF, acute renal failure; RLN, recurrent laryngeal nerve injury; OR, operating room; n/a, not available.

70 years old $(n=5)$ experienced a statistically higher rate of postoperative complications $(100.0 \%$ vs. $34.8 \%, \mathrm{P}=0.013)$. Left-sided resections were associated with increased risk of recurrent laryngeal nerve injury (RLN) compared to rightsided resections ( $36.4 \% v s .0 \%, \mathrm{P}=0.016$ ), and those patients with RLN injury were more likely to be reintubated $(50.0 \%$ vs. $4.2 \%, \mathrm{P}=0.04)$. Bronchopleural fistula occurred in 1 patient $(3.6 \%)$.

\section{Discussion}

Survival in patients facing recurrent lung cancer is quite poor, and completion pneumonectomy can be daunting as depicted in the available literature, which describes discouraging morbidity and mortality rates (8-11). Yet with improvements in local and systemic therapies for NSCLC, thoracic surgeons are likely to encounter patients with recurrent NSCLC without overt contraindications to radical re-resection by completion pneumonectomy. Published series report on heterogeneous cohorts of patients, including those who underwent completion pneumonectomy for benign conditions or metastatic disease from other primary sites, making extrapolation of survival data challenging. Patients undergoing primary pneumonectomy for the treatment of NSCLC at this institution over the same time period experienced a 5 -year overall survival rate of $38.5 \%$. This study concludes that survival rates comparable to primary pneumonectomy can be achieved when facing recurrent disease and re-operative surgery. Interestingly, 7 patients $(25.0 \%)$ had undergone more than one prior resection, making the pneumonectomy a third-time re-operative strategy. Nine patients had prior muscle flap or fat pad coverage of the bronchial stump, which did not appear to affect safe dissection of the hilar structures. In one case, the prior muscle flap was removed and replaced onto the bronchial stump after pneumonectomy. 
Little is published regarding the impact of preoperative chemoradiotherapy on completion pneumonectomy, regardless of histology or indication. In this study, $50.0 \%$ of patients received chemotherapy or chemoradiotherapy prior to completion pneumonectomy. Within the constraints of small sample size, this does not appear to confer a survival advantage. While intuitively, re-operative surgery in the context of chemotherapy and/or radiation could imply a hostile hilar dissection, this does not appear to translate into increased perioperative complications or mortality. However, completion pneumonectomy, as a whole, conferred a $14.3 \%$ 90-day perioperative mortality rate, compared to $7.9 \%$ for patients who underwent primary pneumonectomy at the same institution over the same time period.

Recurrent laryngeal nerve paralysis occurred in 4 patients (36.4\%) who underwent left completion pneumonectomy, which is higher than published studies of primary pneumonectomy (5\% at this institution). This was clinically significant in that there were more reintubations among those patients. Adhesions along the arch of the aorta and mediastinum as well as desmoplastic changes relative to tumor and/or treatment affect may affect preservation of the recurrent laryngeal nerve and predispose to paresis. It is important to consider and discuss this with patients prior to radical resection, particularly of left sided tumors.

While age-related trends in survival did not reach statistical significance, all patients over 70 experienced a complication, and mortality in this age group was higher, approaching significance at 60 days $(\mathrm{P}=0.07)$, and significant at 90 days $(\mathrm{P}=0.01)$. Therefore, age is an important consideration when weighing options for the treatment of locally recurrent lung cancer and may argue for the inclusion of more advanced scoring systems or scales as part of the risk stratification process to aid the identification of patients who will not benefit from completion pneumonectomy.

Limitations of this retrospective review include our inability to capture patients with recurrent disease who were not offered or refused surgery for recurrent disease, which would infer a selection bias. Patients undergoing pneumonectomy in this study were quite fit with high functional status and normal right and left ventricular function. The majority of patients did not have mediastinal nodal disease. Our study would not have captured patients who underwent attempted, but aborted resection, in the setting of node-positive disease, though we expect this represents a rare exception.

Exciting advances in screening, surgical and systemic strategies for NSCLC are changing the landscape of lung cancer and may afford operability to patients previously deemed unresectable. It is feasible that the role of completion pneumonectomy will expand as thoracic surgeons are presented with healthier patients with localized disease, or disease controlled with novel chemo and immunotherapeutic agents. This study demonstrates that completion pneumonectomy, in thoughtfully selected patients, can achieve reasonable survival results. Preoperative evaluation for locoregional nodal disease and metastatic disease should be standard, and considerable attention to functional status and cardiopulmonary reserve is essential. Soft tissue buttress of the bronchial stump is recommended as routine, and intrapericardial dissection is particularly useful to delineate hilar structures in the setting of repeated prior surgery, adhesions and treatment related changes. Careful attention to the recurrent laryngeal nerve, along with expeditious diagnosis and treatment of nerve palsy is crucial in left sided resections.

\section{Acknowledgments}

Funding: None.

\section{Footnote}

Conflicts of Interest: The authors have no conflicts of interest to declare.

Ethical Statement: The authors are accountable for all aspects of the work in ensuring that questions related to the accuracy or integrity of any part of the work are appropriately investigated and resolved. This study was approved by institutional review board of Brigham and Women's Hospital (No. 2006P002482).

Open Access Statement: This is an Open Access article distributed in accordance with the Creative Commons Attribution-NonCommercial-NoDerivs 4.0 International License (CC BY-NC-ND 4.0), which permits the noncommercial replication and distribution of the article with the strict proviso that no changes or edits are made and the original work is properly cited (including links to both the formal publication through the relevant DOI and the license). See: https://creativecommons.org/licenses/by-nc-nd/4.0/.

\section{References}

1. Uramoto H, Tanaka F. Recurrence after surgery in patients 
with NSCLC. Transl Lung Cancer Res 2014;3:242-9

2. Kozu Y, Maniwa T, Takahashi S, et al. Risk factors for both recurrence and survival in patients with pathological stage I non-small-cell lung cancer. Eur J Cardiothorac Surg 2013;44:e53-8.

3. Wright G, Manser RL, Byrnes G, et al. Surgery for nonsmall cell lung cancer: systematic review and meta-analysis of randomised controlled trials. Thorax 2006;61:597-603.

4. Deslauriers J, Grégoire J. Surgical therapy of early nonsmall cell lung cancer. Chest 2000;117:104S-109S.

5. Whitson BA, Groth SS, Duval SJ, et al. Surgery for earlystage non-small cell lung cancer: a systematic review of the video-assisted thoracoscopic surgery versus thoracotomy approaches to lobectomy. Ann Thorac Surg 2008;86:200816; discussion 2016-8.

6. National Comprehensive Cancer Network. Non-Small Cell Lung Cancer (Version 3.2018). Available online: http://www.nccn.org/professionals/physician_gls/pdf/ nsclc.pdf. Accessed April 6, 2018.

7. Cardillo G, Galetta D, van Schil P, et al. Completion pneumonectomy: a multicentre international study on 165 patients. Eur J Cardiothorac Surg 2012;42:405-9.

Cite this article as: White A, Kucukak S, Lee DN, Bueno R, Jaklitsch M, Mentzer S, Sugarbaker D, Wee J, Swanson SJ. Completion pneumonectomy is safe and effective in select patients with recurrent non-small cell lung cancer. J Thorac Dis 2020;12(3):217-222. doi: 10.21037/jtd.2020.01.51
8. Tabutin M, Couraud S, Guibert B, et al. Completion pneumonectomy in patients with cancer: postoperative survival and mortality factors. J Thorac Oncol 2012;7:1556-62.

9. Kasprzyk M, Sławiński G, Musik M, et al. Completion pneumonectomy and chemoradiotherapy as treatment options in local recurrence of non-small-cell lung cancer. Kardiochir Torakochirurgia Pol 2015;12:18-25.

10. Puri V, Tran A, Bell JM, et al. Completion pneumonectomy: outcomes for benign and malignant indications. Ann Thorac Surg 2013;95:1885-91.

11. Miller DL, Deschamps C, Jenkins GD, et al. Completion pneumonectomy: factors affecting operative mortality and cardiopulmonary morbidity. Ann Thorac Surg 2002;74876-83; discussion 883-4.

12. Grégoire J, Deslauriers J, Guojin L, et al. Indications, risks, and results of completion pneumonectomy. J Thorac Cardiovasc Surg 1993;105:918-24.

13. Fujimoto T, Zaboura G, Fechner S, et al. Completion pneumonectomy: current indications, complications, and results. J Thorac Cardiovasc Surg 2001;121:484-90. 